\title{
Acupuncture in the Management of Trigeminal Neuralgia
}

Edwards, James; Shaw, Vivien

\section{Acupuncture in medicine : journal of the British Medical Acupuncture Society}

DOI:

$10.1177 / 0964528420924042$

Published: 01/06/2021

Peer reviewed version

Cyswllt i'r cyhoeddiad / Link to publication

Dyfyniad o'r fersiwn a gyhoeddwyd / Citation for published version (APA):

Edwards, J., \& Shaw, V. (2021). Acupuncture in the Management of Trigeminal Neuralgia. Acupuncture in medicine : journal of the British Medical Acupuncture Society, 39(3), 192-199. https://doi.org/10.1177/0964528420924042

\footnotetext{
Hawliau Cyffredinol / General rights

Copyright and moral rights for the publications made accessible in the public portal are retained by the authors and/or other copyright owners and it is a condition of accessing publications that users recognise and abide by the legal requirements associated with these rights.

- Users may download and print one copy of any publication from the public portal for the purpose of private study or research.

- You may not further distribute the material or use it for any profit-making activity or commercial gain

- You may freely distribute the URL identifying the publication in the public portal ?
}

Take down policy

If you believe that this document breaches copyright please contact us providing details, and we will remove access to the work immediately and investigate your claim. 


\title{
Acupuncture in the Management of Trigeminal Neuralgia
}

\author{
James W. Edwards. ${ }^{1+}$ Vivien Shaw. ${ }^{1}$ \\ ${ }^{1}$ School of Medical Sciences, Bangor University, Bangor, Wales \\ +Corresponding author. Email: jwedwards1@uclan.ac.uk
}

\section{ABSTRACT}

Aims To assess the standing of acupuncture as a clinical tool in the management of trigeminal neuralgia against the current first-line drug and the most effective surgery.

Methods Data regarding efficacy, side-effects, and cost were compiled for each of the three modalities from the PubMed and Cochrane Library databases. Patient stress was estimated according to Holmes and Rahe's Social Readjustment Rating Scale (SRRS).

Results Acupuncture is not significantly more effective than its corresponding control $(p=0.088)$, but has the greatest mean efficacy of the modalities considered (acupuncture $86.5 \% \pm 5.6 \%(95 \%$ confidence interval), surgery $79.3 \% \pm 7.7 \%$, pharmacotherapy $71.7 \% \pm 2.5 \%)$. Acupuncture also had fewer mean reported side-effects (acupuncture $22.7 \% \pm 5.9 \%$, surgery $25.3 \% \pm 12.6 \%$, pharmacotherapy $88.8 \% \pm 25.0 \%$ ) and lowest cost: after 5 years acupuncture cost $£ 750$, carbamazepine $£ 1507.73$ and microvascular decompression $£ 4878.42$. Acupuncture was the least stressful according to the SRRS (53 points), surgery the next most stressful (153 points) and pharmacotherapy was the most stressful intervention to patients (217 points).

Conclusion Acupuncture appears more effective than pharmacotherapy or surgery. Statistical analysis of side-effects was not possible due to inconsistent reporting protocols, but the data indicate acupuncture is considerably safer than pharmacotherapy or surgery. Acupuncture is also the least expensive therapeutic modality to deliver long-term (67 weeks onwards), and our analysis indicates that it is less stressful to patients than pharmacotherapy or surgery. Further study into these areas and the practicality of its availability on the NHS is recommended. 


\section{INTRODUCTION}

Trigeminal neuralgia (TN) is characterised by excruciating, burning pain along one or more branches of the trigeminal nerve, which can be triggered by innocuous stimuli like talking, chewing, or shaving, and may last seconds to minutes. In most cases, TN is caused by compression of the nerve root by an aberrant artery as it leaves the pons.

Affecting up to 26.8 individuals per 100,000 , TN is primarily seen in the $6^{\text {th }}$ decade of life or later. ${ }^{1}$

Treatments for TN are broadly classified into three divisions:

1. Surgery. Surgical interventions are generally classified into three sub-types:

i. Microvascular decompression (MVD): craniotomy and placement of a Teflon sponge to protect nerve root from arterial pulsation.

ii. Percutaneous interventions: including glycerol rhizotomy, radiofrequency lesioning, and balloon compression.

iii. Stereotactic radiosurgery: focused ionising radiation damaging the nerve root, preventing pain signal transmission.

2. Pharmacotherapy. NICE Guideline CG173 states carbamazepine is the first-line drug for TN. Carbamazepine inhibits voltage-gated Na channels in neurones, ${ }^{1}$ reducing the frequency of pain signals processed by the central nervous system.

3. Complementary. Recent research suggests acupuncture may alleviate TN symptoms. 


\section{METHODS}

\section{Literature Search}

Two acupuncture studies were sourced from the Cochrane Library, with the remainder found on PubMed. The reference lists within these papers provided supplementary titles. PubMed search terms were: "acupuncture AND trigeminal” ( $n=217$ results), "trigeminal neuralgia AND microvascular decompression" ( $n=959)$, and "carbamazepine AND trigeminal neuralgia" ( $n=722)$. Filters "Species: Human", "Full Text" and "Language: English" were applied, giving 272 results (acupuncture $=17$, microvascular decompression $=206$, pharmacotherapy $=49$ ). The filtered titles were then assessed, and papers aligning with the scope of this study were selected.

\section{Multifactorial Comparison}

It is beyond the scope of this study to consider all surgical options available, therefore MVD was selected to be the focus of the surgical arm of the comparison. While it is understood that MVD is not representative of the whole gamut of surgical options (MVD is an open procedure, while many others - including balloon compression, glycerol rhizotomy, or stereotactic radiosurgery - are percutaneous or entirely non-invasive), it is reported to have the best long-term results with the lowest recurrence rate, and relatively few complications. ${ }^{2}$

Carbamazepine is the focus of the pharmacotherapeutic arm of the comparison as it is the current first-line NICE-recommended therapy.

A structured comparison of the three management modalities for TN was performed based on four key elements:

1. Efficacy - efficacy rates were often reported within studies. These are usually percentages of patients experiencing 'significant improvement' under a given treatment. Statistical testing for significant differences between modalities' success rates was conducted using a one-way Kruskal-Wallis test for independent samples after data from the literature was compiled. 
2. Side-effects and complications - while mentioned in some studies, additional studies focusing on side-effects were included. Obtaining directly comparable data on side-effects was challenging and did not support statistical analysis.

3. Patient stress - considered in this study through the impact to a patient's lifestyle caused by each modality using the Holmes \& Rahe Social Readjustment Rating Scale (SRRS). ${ }^{3}$ Stress to patients is not often considered in studies assessing treatment efficacy, and as such no stress-assessing protocols were followed at the point of primary data collection. Therefore, the SRRS is the only protocol available to assess stress levels caused by each modality in the context of this study. Statistically analysing summed stress scores like these is impossible; the outcome would be meaningless as the summed score represents a sample of $n=1$. Instead, Jaccard coefficients for score distribution for each pair of modalities were calculated. This offers a quantitative opportunity to evaluate similarity in stress profiles.

4. Cost - cost for acupuncture treatment on the NHS was found on the British Medical Acupuncture Society website and through personal communication (Cummins, M. (2017), Personal communication.). NICE issued a costing report including carbamazepine which was used to assess pharmacotherapy cost. ${ }^{4}$ There were no reports of MVD cost to the NHS and, when contacted, NICE, NHS England and NHS Improvement were unable to provide the information. Instead, reported surgical costs from two papers ${ }^{5,6}$ were converted to GBP considering the appropriate average annual exchange rates for those years. 


\section{RESULTS}

\section{$\underline{\text { Acupuncture }}$}

Efficacy rates for all modalities are summarised in Table 1.

Side-effects from acupuncture are rare: one study reported 2,108 negative side-effects from 9,277 treatments ${ }^{7}$ and another showed 2,178 negative side-effects from 31,822 treatments: ${ }^{8}$ a combined 10.4\% risk. Most commonly reported were: transient symptom exacerbation, bleeding, and administrative problems (eg needles lost). On the whole, acupuncture side-effects are mild (not lifethreatening); however, from 302,636 acupuncture treatments, ${ }^{9,10} 3$ cases of iatrogenic pneumothorax were reported: less than a $0.001 \%$ risk.

Acupuncture in NHS primary care costs $£ 25$ per treatment. The cost-assessment model used was: 12 initial sessions ( 6 weekly treatments, then 6 monthly treatments) with quarterly 'maintenance' treatments.

\section{Surgery}

MVD is often studied in the context of differing efficacy rates between young and elderly patients. 11-14 The initial limitation is the lack of consensus defining "elderly". Papers with a defining age of $\geq 60$ years were included in this study, including a larger proportion of data.

Side-effects and complications of MVD are serious, including: meningitis, cerebrospinal fluid (CSF) leak, and death. Four studies discussed side-effect and complication frequency: ${ }^{11-14}$ a Mann-Whitney $U$ test found no significant difference in rates of complications per patient $(N=8, U=13, p=0.200)$.

MVD cost was approximated at $£ 4878.42$ per surgery.

\section{Pharmacotherapy}

It is estimated that $75 \%$ of patients undergoing carbamazepine therapy experience symptomatic relief. ${ }^{1}$ Despite this efficacy, many patients will experience side-effects including cognitive suppression, dizziness, cardiovascular disturbance, and the inflammatory skin reaction Stevens- 
Johnson Syndrome (SJS). ${ }^{15,16}$ These may seriously affect patient stress, not just in initial diagnosis but throughout subsequent treatment and its side-effects which may cause lifestyle changes.

NICE's costing statement for carbamazepine therapy ${ }^{4}$ shows $28 \times 200 \mathrm{mg}$ carbamazepine tablets costing f5.78. In the statement, prices are rounded too early, causing a slight inaccuracy. This equation demonstrates the calculation of daily (A) and annual (B) costs of a normal daily carbamazepine dose $-800 \mathrm{mg}:{ }^{4}$

$$
\begin{gathered}
A=\left(\frac{£ 5.78}{28}\right) \times 4=£ 0.8257 \\
B=A \times 365=£ 301.3805
\end{gathered}
$$

\begin{tabular}{|c|c|c|c|}
\hline STUDY & $\begin{array}{l}\text { PATIENTS IN TREATMENT } \\
\text { ARM(S) (N) }\end{array}$ & $\begin{array}{l}\text { “CURED” OR “SIG. } \\
\text { IMPROVEMENT” (N) }\end{array}$ & SUCCESS RATE (\%) \\
\hline \multicolumn{4}{|c|}{ ACUPUNCTURE } \\
\hline 17 & 30 & 23 & 76.7 \\
\hline 18 & 86 & 72 & 83.7 \\
\hline 19 & 57 & 56 & 98.2 \\
\hline 20 & 65 & 57 & 87.7 \\
\hline 21 & 90 & 77 & 85.6 \\
\hline 22 & 62 & 54 & 87.1 \\
\hline Total & 392 & 341 & 86.5 \\
\hline \multicolumn{4}{|c|}{ SURGERY } \\
\hline 13 & 124 & 73 & 58.9 \\
\hline 12 & 99 & 88 & 88.9 \\
\hline 11 & 59 & 50 & 84.7 \\
\hline 23 & 13,805 & 11,596 & 84.0 \\
\hline 24 & 31 & 25 & 80.6 \\
\hline 25 & 6,847 & 5,717 & 83.5 \\
\hline 26 & 53 & 47 & 88.7 \\
\hline 27 & 20 & 13 & 65.0 \\
\hline Total & 21,038 & 17,609 & 79.3 \\
\hline \multicolumn{4}{|c|}{ PHARMACOTHERAPY } \\
\hline 1 & $100^{*}$ & $75^{*}$ & 75.0 \\
\hline 28 & 123 & 88 & 71.5 \\
\hline 29 & 81 & 55 & 67.9 \\
\hline Total & 304 & 218 & 71.5 \\
\hline
\end{tabular}

Carbamazepine costs $82.6 p$ per day: $€ 301.38$ annually. 


\section{Statistical Analysis}

A one-way Kruskal-Wallis test for independent samples found the three modalities' efficacy rates were not statistically significant ( $D F=2, H=4.850, p=0.088$ ), likely due to small sample sizes $(n=6,8$ and 3 respectively for acupuncture, surgery, and pharmacotherapy). Statistical side-effect analysis proved impossible due to different measurement and reporting protocols between studies, but the data do suggest pharmacological interventions cause many more side-effects than acupuncture or surgery. Overall, acupuncture's stress factor profile is the most distinctive - see Table 4 for scores. A score of 0 indicates no shared factors and 1 a complete overlap. Surgery and pharmacotherapy score 0.625 , indicating most shared stress factors and therefore a similar stress profile. 


\section{DISCUSSION}

\section{Efficacy}

"Cured" in the context of TN studies represents no relapse of symptoms before the follow-up: from the papers, this ranges from two treatment cycles to six months. ${ }^{17-22}$ In the literature, acupuncture's "cured" rate is higher in the intervention arm than the control, excluding Yang et al ${ }^{17}$ for whom no data concerning "cured" rates was available. This represents an average of $86.5 \%$ cases "cured" or "significantly improved" by acupuncture. Alleviation of pain may also be due to reduction of secondary myofascial pain which is known to develop in response to chronic pain stimuli: ${ }^{2}$ while not a management modality for TN directly, this is still a positive outcome which may indirectly manage symptoms.

Eight MVD studies ${ }^{11-13,23-27}$ had an average of $79.3 \%$ "cured" or "significantly improved". Two studies collecting primary and secondary data on carbamazepine therapy ${ }^{28,29}$ found a $70 \%$ efficacy rate, with a third reporting a 75\% efficacy. Table 1 compares these data: acupuncture is the most effective modality (86.5\%) and carbamazepine the least (71.5\%).

One study with 62 participants reported a mean reduction of 0.8 in the Visual Analogue Scale (VAS) from the baseline to the end of acupuncture treatment. ${ }^{30}$ This fell a further 0.9 points at a 6 -week review. Both were statistically significant changes $(p=<0.05)$.

Another study ${ }^{31}$ only had 15 participants but showed a similar pattern, with a reduction of 0.8 in the VAS from baseline to the end of treatment and again from the end of treatment to the 6-month review.

Despite many studies reporting significant efficacy rates (and the percentage efficacy rates are suggestively higher for acupuncture than surgery or pharmacotherapy), our statistical analysis was inconclusive ( $p=0.088$, Kruskal-Wallis). This is due to a small sample size and represents an area for future study. 


\section{Side-Effects}

Patient anonymisation limits side-effect analysis - it is impossible to calculate how many patients experienced $>1$ side-effect. While not a true risk representation, a percentage can be drawn from "side-effects reported $(n)$ " and "patients $(n)$ ". This limitation is common to all three modalities.

Table 2 compares the data: pharmacotherapy causes significantly more side-effects than acupuncture or surgery $(p=<0.01)$. Research suggests women have lower carbamazepine tolerance by a factor of approximately $1.5,{ }^{15}$ which may have some indication for varying serum drug level thresholds for symptoms between the sexes.

Pharmacotherapy's $88.8 \%$ side-effect is the highest of the modalities - acupuncture is lowest at 22.7\%. Variable reporting, small sample sizes of applicable papers and patient anonymisation prevent robust statistical analysis, but awareness of the difference in overall prevalence of sideeffects from pharmacotherapy and acupuncture/surgery is important for physicians and patients alike.

\begin{tabular}{|c|c|c|c|c|}
\hline MODALITY & PAPERS (N) & PATIENTS (N) & $\begin{array}{l}\text { SIDE-EFFECTS } \\
\text { REPORTED (N) }\end{array}$ & MEAN (Cl) \\
\hline ACUPUNCTURE & 3 & 9,308 & 2,113 & $22.7 \%( \pm 5.9 \%)$ \\
\hline SURGERY & 12 & 27,638 & 6,989 & $25.3 \%( \pm 12.6 \%)$ \\
\hline PHARMACOTHERAPY & 5 & 385 & 34 & $88.8 \%( \pm 25.0 \%)$ \\
\hline \multicolumn{5}{|c|}{$\begin{array}{l}\text { Table } 2 \text { mean side-effect frequencies from the modalities: } \text { acupuncture }^{7,17,32} \text {, surgery } \\
\text { pharmacotherapy } 11,12,36,37,14,23-26,33-35 \text { and }\end{array}$} \\
\hline \multirow{2}{*}{\multicolumn{5}{|c|}{$\begin{array}{l}\text { Side-effect severity is also significant: rarely, acupuncture may exert serious side-effects (al } \\
\text { these carry a minuscule risk). Pharmacotherapy brings substantial side-effects in cognitive }\end{array}$}} \\
\hline & & & & \\
\hline \multicolumn{5}{|c|}{ suppression and the risk of SJS in those genetically predisposed; however, these should be } \\
\hline \multicolumn{5}{|c|}{ considered against the severity of side-effects from surgery: death, meningitis, CSF leak or cranial } \\
\hline \multicolumn{5}{|c|}{ nerve palsy. Surgical interventions may also significantly impact masticatory function or alter } \\
\hline
\end{tabular}




\section{Patient Stress}

Evaluating patient stress is subjective, difficult and often overlooked, and there is no clinical definition or measurement scale for iatrogenic stress. On the other hand, some rating systems make it possible to account for the stress caused by some aspects of medical interventions: indeed, according to the SRRS, one MVD surgery can provide over half the points to predispose someone to moderate illness within 12 months $^{3}$ - see Table 3 .

Table 3 compares each modality's SRRS score. Each receives a score of 53 - personal injury / illness to account for the initial diagnosis of TN. MVD requires recovery leave from work and refraining from driving, and repeated prescriptions in England may be a drain on financial resources in lowerincome households, hence both represent a "change in financial state". For the same reason, MVD scores for "change in work hours" and "change in social activities". Carbamazepine's cognitive suppression means it applies to all selected life events, earning it the highest score of 217 . Within a 12 -month period, $<150$ points represents a $30 \%$ risk of illness, $150-300$ a $50 \%$ risk and $>300$ an $80 \%$ risk. $^{3}$

\begin{tabular}{l|ccc} 
LIFE EVENT & SURGERY & PHARMACOTHERAPY & ACUPUNCTURE \\
\hline PERSONAL INJURY / ILLNESS & 53 & 53 & 53 \\
CHANGE IN FINANCIAL STATE & 38 & 38 & - \\
CHANGE IN RESPONSIBILITIES AT WORK & - & 29 & - \\
REVISION OF PERSONAL HABITS & 24 & 24 & - \\
CHANGE IN WORK HOURS / CONDITIONS & 20 & 20 & - \\
CHANGE IN RECREATION & - & 19 & - \\
CHANGE IN SOCIAL ACTIVITIES & 18 & 18 & 53 \\
CHANGE IN SLEEPING HABITS & - & 16 & - \\
Table 3 - scores incurred by each modality according to Holmes \& Rahe's Social Readjustment Rating Scale. \\
Pharmacotherapy is the most stressful intervention according to the SRRS (217 points). Surgery is \\
the next most stressful at 153, and acupuncture the least stressful with just 53 points from the initial \\
diagnosis. Statistical analysis of these data is impossible, but Jaccard similarity indices demonstrate \\
overlap of stress factors (Table 4):
\end{tabular}




\begin{tabular}{c|ccc} 
& ACUPUNCTURE & SURGERY & PHARMACOTHERAPY \\
\hline ACUPUNCTURE & 1 & 0.2 & 0.125 \\
SURGERY & - & 1 & 0.625 \\
PHARMACOTHERAPY & - & - & 1 \\
Table 4 - Jaccard similarity coefficients for stress factor profiles of each modality. Jaccard coefficients compare
\end{tabular}

presence/absence score distributions (eg stress factors) in multiple treatment types. $0=$ no similarity, $1=$ identical.

These scores suggest acupuncture's stress profile is most distinctive, scoring low compared to surgery/pharmacotherapy. Surgery and pharmacotherapy have a more similar stress profile, scoring 0.625 .

$\underline{\text { Cost }}$

Figure 1 demonstrates the cost relationship of the three management modalities over a 30-year period.

Acupuncture costs the NHS $£ 25$ per treatment - priced according to the standardised treatment plan, the cost rises sharply at first but after 65 weeks of treatment, acupuncture becomes the least expensive option. After 5 years of treatment, acupuncture represents half the cost of carbamazepine. In the $17^{\text {th }}$ year of treatment, carbamazepine becomes more expensive than one MVD. Acupuncture remains the least expensive option until the $47^{\text {th }}$ year of treatment, assuming that:

1) The patient was young enough when diagnosed to live another 47 years (the global life expectancy is 71.4 years according to the WHO website, meaning the patient would have to be in their mid-twenties at diagnosis), and

2) The next cheapest therapeutic intervention at the $47^{\text {th }}$ year (MVD) had not failed by that point (MVD can fail after $20-26$ years), ${ }^{40}$ and

3) Symptoms had not been alleviated before the $47^{\text {th }}$ year of treatment: usually, acupuncture treatments are stopped after 4 quarterly treatments have elapsed with no relapse of symptoms.

The costs demonstrated in Figure 1 assume no relapses, well-tolerated drugs or surgeries, and minimal impact of side-effects to present a simple image. 
The long-term treatment required in cases of trigeminal neuralgia is met by a long-term cost analysis. Acupuncture very quickly becomes, and remains, the least expensive therapeutic arm of the three, and surgery the most expensive.

\section{Strengths and Limitations}

To the authors' knowledge, this study is the first of its kind to compare these three TN management modalities. Further, it is believed to be the first three-way cost analysis, which may support the argument for clinical application of acupuncture. Although detailed statistical analysis of each modality's outcomes was not possible, some preliminary quantitative evidence has been produced which may be developed as further efficacy, side-effects and stress research is conducted. The greatest statistical challenge was the sample sizes, limited by the wide scope of the study.

This study's main limitation is that patients facing surgery for TN are likely to have refractory TN; the effects of acupuncture on refractory and non-refractory TN have not been elucidated. Further, distinctions between surgical techniques are commonly noted throughout literature, as well as between medications; however, manual versus electroacupuncture has not been considered in a number of these studies. Another limitation is the subjectivity of patient stress and how it may be applied, especially quantitively. This will remain a challenge until stress measures are more routinely included in study findings, when statistical analysis may become possible.

\section{Conclusion}

This study shows that acupuncture treatment for TN is effective, safe, and cheaper to deliver than surgical or pharmacotherapeutic interventions. The results warrant further detailed research into the efficacy, patient stress and side-effects of acupuncture versus surgery and pharmacotherapy. Further research is also recommended to assess the practicality of offering acupuncture as a management modality for trigeminal neuralgia through the NHS. 
Finally, treatments offered by the NHS must be cost-effective. While carbamazepine is less expensive than MVD, acupuncture is by far the least expensive option. Further research should be conducted with a view to considering acupuncture as a first-line therapy for TN.

\section{Acknowledgements}

The authors wish to thank Dr Isabelle Winder of Bangor University for her statistical assistance.

\section{Conflict of Interest}

None declared.

\section{REFERENCES}

1. Al-Quliti KW. Update on neuropathic pain treatment for trigeminal neuralgia. The pharmacological and surgical options. Neurosciences (Riyadh). 2015 Apr;20(2):107-14.

2. Ichida MC, de Almeida AN, da Nobrega JCM, Teixeira MJ, de Siqueira JTT, de Siqueira SRDT. Sensory abnormalities and masticatory function after microvascular decompression or balloon compression for trigeminal neuralgia compared with carbamazepine and healthy controls. J Neurosurg. 2015;122(6):1315-23.

3. Holmes TH, Rahe RH. The Social Readjustment Rating Scale. J Psychosom Res. 1967 Aug;11(2):213-8.

4. National Institute for Health and Care Excellence (NICE). Neuropathic pain - pharmacological management: the pharmacological management of neuropathic pain in adults in nonspecialist settings Costing statement [Internet]. 2013 [cited 2017 Nov 29]. p. 1-7. Available 
from: https://www.nice.org.uk/guidance/cg173/resources/costing-statement-pdf-191617453

5. Tarricone R, Aguzzi G, Musi F, Fariselli L, Casasco A. Cost-effectiveness analysis for trigeminal neuralgia: Cyberknife vs microvascular decompression. Neuropsychiatr Dis Treat. 2008 Jun;4(3):647-52.

6. Fransen P. Cost-effectiveness in the surgical treatments for trigeminal neuralgia. Acta Neurol Belg. 2012 Sep 9;112(3):245-7.

7. Odsberg A, Schill U, Haker E. Acupuncture treatment: side effects and complications reported by Swedish physiotherapists. Complement Ther Med. 2001 Mar 1;9(1):17-20.

8. White A, Hayhoe S, Hart A, Ernst E. Adverse events following acupuncture: prospective survey of 32000 consultations with doctors and physiotherapists. Br Med J (Clin Res Ed). 2001 Sep 1;323(7311):485-6.

9. Witt CM, Pach D, Brinkhaus B, Wruck K, Tag B, Mank S, et al. Safety of Acupuncture: Results of a Prospective Observational Study with 229,230 Patients and Introduction of a Medical Information and Consent Form. Forsch Komplementmed. 2009;16:91-7.

10. Witt CM, Pach D, Reinhold T, Wruck K, Brinkhaus B, Mank S, et al. Treatment of the adverse effects from acupuncture and their economic impact: A prospective study in 73,406 patients with low back or neck pain. Eur J Pain. 2011 Feb 1;15(2):193-7.

11. Yang $\mathrm{D}$, Wang $\mathrm{Z}$, Jiang $\mathrm{D}$, Chen $\mathrm{H}$. The efficacy and safety of microvascular decompression for idiopathic trigeminal neuralgia in patients older than 65 years. J Craniofac Surg. 2014 Jul;25(4):1393-6.

12. Amagasaki K, Watanabe S, Naemura K, Shono N, Nakaguchi H. Safety of microvascular decompression for elderly patients with trigeminal neuralgia. Clin Neurol Neurosurg. 2016 Feb;141:77-81. 
13. Bick SKB, Huie D, Eskandar EN. Older Patients Have Greater Improvements in Pain Score Following Microvascular Decompression. Neurosurgery. 2016 Aug;63 Suppl 1:176.

14. Phan K, Rao PJ, Dexter M. Microvascular decompression for elderly patients with trigeminal neuralgia. J Clin Neurosci. 2016 Jul 1;29:7-14.

15. Besi E, Boniface DR, Cregg R, Zakrzewska JM. Comparison of tolerability and adverse symptoms in oxcarbazepine and carbamazepine in the treatment of trigeminal neuralgia and neuralgiform headaches using the Liverpool Adverse Events Profile (AEP). J Headache Pain. 2015 Dec 3;16(81):1-7.

16. Can i, Tholakanahalli V. Carbamazepine-induced atrioventricular block in an elderly woman. Turk Kardiyol Dern Ars. 2016;44(1):68-70.

17. Yang J-X, Zhang J-P, Yu J-C, Han J-X. [Clinical research of primary trigeminal neuralgia treated with electroacupuncture at qi streets acupoints combined with spinal regulation therapy]. Chinese Acupunct Moxibustion. 2014 Aug;34(8):763-8.

18. Peng $Y-Y$, Huang $Y-S$, Zhang S-L, Ye X-Y, Xiong Z-R, Cao J. [Clinical observation on threecombination needling method for treatment of primary trigeminal neuralgia]. Chinese Acupunct Moxibustion. 2008 Oct;28(10):715-8.

19. Zhou C, Kong D, Han Z. [Clinical observation on acupoint injection of VitB12 for treatment of trigeminal neuralgia]. Chinese Acupunct Moxibustion. 2007 Sep;27(9):668-70.

20. He L, Zhang X. Clinical effect of sphenopalatine ganglion needling in treating primary trigeminal neuralgia of liver-yang upsurge syndrome type. Chin J Integr Med. 2012 Mar 2;18(3):214-8.

21. Zhang X. [Therapeutic effect of deep acupuncture at local acupoints on trigeminal neuralgia]. Chinese Acupunct Moxibustion. 2005 Aug;25(8):549-50. 
22. Sold-Darseff J, Leydhecker W. [Acupuncture for pain in the cranial region and blepharospasm without organic cause]. Klin Monbl Augenheilkd. 1986 Aug 11;189(2):167-9.

23. Gubian A, Rosahl SK. Meta-Analysis on Safety and Efficacy of Microsurgical and Radiosurgical Treatment of Trigeminal Neuralgia. World Neurosurg. 2017 Jul 1;103:757-67.

24. Inoue T, Hirai H, Shima A, Suzuki F, Fukushima T, Matsuda M. Diagnosis and management for trigeminal neuralgia caused solely by venous compression. Acta Neurochir (Wien). 2017 Apr $20 ; 159(4): 681-8$.

25. Xia L, Zhong J, Zhu J, Wang Y-N, Dou N-N, Liu M-X, et al. Effectiveness and Safety of Microvascular Decompression Surgery for Treatment of Trigeminal Neuralgia: A Systematic Review. J Craniofac Surg. 2014;25(4):1413-7.

26. Khan S, Khan B, Khan A, Afridi E, Mehmood S, Muhammad G, et al. Microvascular Decompression for Trigeminal Neuralgia. J Ayub Med Coll Abbottabad. 2015;27(3):539-42.

27. Nanda A, Javalkar V, Zhang S, Ahmed O. Long term efficacy and patient satisfaction of microvascular decompression and gamma knife radiosurgery for trigeminal neuralgia. J Clin Neurosci. 2015 May;22(5):818-22.

28. Oomens MAE-M, Forouzanfar T. Pharmaceutical Management of Trigeminal Neuralgia in the Elderly. Drugs Aging. 2015 Sep 4;32(9):717-26.

29. Benoliel R, Zini A, Khan J, Almoznino G, Sharav Y, Haviv Y. Trigeminal neuralgia (part II): Factors affecting early pharmacotherapeutic outcome. Cephalalgia. 2016;36(8):747-59.

30. Gao J, Zhao C, Jiang W, Zheng B, He Y. Effect of Acupuncture on Cognitive Function and Quality of Life in Patients With Idiopathic Trigeminal Neuralgia. J Nerv Ment Dis. 2019;207(3):171-4.

31. Ichida MC, Zemuner M, Hosomi J, Pai HJ, Teixeira MJ, de Siqueira JTT, et al. Acupuncture 
Treatment for Idiopathic Trigeminal Neuralgia: A Longitudinal Case-Control Double Blinded Study. Chin J Integr Med. 2017;23(11):829-36.

32. Sert H, Usta B, Muslu B, Gözdemir M. Successful treatment of a resistance trigeminal neuralgia patient by acupuncture. Clinics (Sao Paulo). 2009;64(12):1225-6.

33. Lemos L, Alegria C, Oliveira J, Machado A, Oliveira P, Almeida A. Pharmacological versus microvascular decompression approaches for the treatment of trigeminal neuralgia: clinical outcomes and direct costs. J Pain Res. 2011;4:233-44.

34. Xia L, Liu M-X, Zhong J, Dou N-N, Li B, Sun H, et al. Fatal complications following microvascular decompression: could it be avoided and salvaged? Neurosurg Rev. 2017 Jul 12;40(3):389-96.

35. Bartek J, Gulati S, Unsgård G, Weber C, Förander P, Solheim O, et al. Standardized reporting of adverse events after microvascular decompression of cranial nerves; a population-based single-institution consecutive series. Acta Neurochir (Wien). 2016 Sep 4;158(9):1775-81.

36. Hitchon PW, Holland M, Noeller J, Smith MC, Moritani T, Jerath N, et al. Options in treating trigeminal neuralgia: Experience with 195 patients. Clin Neurol Neurosurg. 2016 Oct;149:166-70.

37. Liebelt BD, Barber SM, Desai VR, Harper R, Zhang J, Parrish R, et al. Superior Petrosal Vein Sacrifice During Microvascular Decompression: Perioperative Complication Rates and Comparison with Venous Preservation. World Neurosurg. 2017 Aug 1;104:788-94.

38. Anjum N, Polak ME, Ardern-Jones M, Cooper HL. Presence of the HLA-A*3101 allele in a familial case of drug reaction with eosinophilia and systemic symptoms, secondary to carbamazepine. Clin Exp Dermatol. 2014 Apr 1;39(3):307-9.

39. Sathasivam HP, Ismail S, Ahmad AR, Basri NN, Muhamad H, Mohd. Tahir NF, et al. Trigeminal neuralgia: a retrospective multicentre study of 320 Asian patients. Oral Surg Oral Med Oral Pathol Oral Radiol. 2017 Jan;123(1):51-7. 
40. Inoue H, Kondo A, Shimano H, Yasuda S, Murao K. Reappearance of Cranial Nerve Dysfunction Symptoms Caused by New Artery Compression More than 20 Years after Initially Successful Microvascular Decompression: Report of Two Cases. Neurol Med Chir (Tokyo). 2016;56(2):77-80. 